\title{
Método situacional e sua influência no conhecimento tático processual de escolares
}

\author{
Silvia Teixeira de Pinho ${ }^{1}$ \\ Daniel Medeiros Alves ${ }^{1}$ \\ Pablo Juan Greco ${ }^{2}$ \\ José Francisco Gomes Schild ${ }^{1}$ \\ ${ }^{1}$ Escola Superior de Educação Física da Universidade Federal de Pelotas, RS, Brasil \\ ${ }^{2}$ Escola de Educação Física, Fisioterapia e Terapia Ocupacional da Universidade \\ Federal de Minas Gerais, Belo Horizonte, MG, Brasil
}

\begin{abstract}
Resumo: O propósito do presente estudo foi verificar a influência da aplicação de jogos situacionais, sobre os níveis de Conhecimento Tático Processual (CTP) em escolares, na modalidade de handebol. A amostra foi constituída por 35 sujeitos de ambos os sexos na faixa etária entre 10-12 anos. Foram divididos 2 grupos, $(1-$ Situacional $)$ e $(2-$ Misto $=$ Analítico + Global $)$. Para o processo de categorização dos métodos de ensino foram filmadas 18 aulas e utilizado o protocolo de Stefanello (1999). Para a avaliação do CTP foi utilizado o teste KORA, desenvolvido por Memmert (2002). Os resultados confirmaram que no grupo 1 houve uma melhoria no CTP dos alunos em todos os parâmetros. Por outro lado, o grupo 2 não apresentou melhora significativa em nenhum dos parâmetros analisados. Portanto, conclui-se que o método de ensino centrado nas capacidades táticas (situacional) é eficaz para estimular o desenvolvimento do conhecimento tático processual.
\end{abstract}

Palavras-chave: Método situacional. Conhecimento tático declarativo.

\section{Method situacional and its influence in the procedural tactical pertaining to school knowledge}

\begin{abstract}
The purpose of this study was to assess the influence of the situational games, on the levels of knowledge Tactical Procedure (CTP) in schoolchildren, in the form of handball. The sample consisted of 35 subjects of both sexes aged 10-12 years. Were divided 2 groups, ( 1 - Situational) and (2 - Joint Analytical + = Global). For the categorization process of teaching methods were videotaped 18 lessons and used the protocol of Stefanello (1999). For the evaluation of the CTP test was used KORA, developed by Memmert (2002). The results confirmed that in group 1 there was an improvement in CTP of students in all parameters. Moreover, group 2 showed no significant improvement in the parameters analyzed. Therefore, we conclude that the teaching method focuses on tactical skills (situational) is effective in stimulating the development of procedural tactical knowledge.
\end{abstract}

Key Words: Situational method. Procedural tactical knowledge.

\section{Introdução}

Por meio de observações assistemáticas da prática pedagógica escolar percebe-se que há uma cobrança dos professores de Educação Física para que os alunos sejam inteligentes e criativos nas suas ações nos esportes, ou seja, que realizem gestos e ações motoras que desconhecem. Embora sejam claras as preocupações destes profissionais com estes aspectos, os alunos não são estimulados através do ensino proposto por alguns métodos de ensino no cotidiano escolar.

Segundo Corrêa et al (2004), o conhecimento de como ensinar é uma preocupação que acompanha aqueles que ensinam. Qual professor nunca se questionou sobre este aspecto?
Para Freire (1997), o papel do professor é criar para o aluno condições de desequilíbrio, apresentando para ele o novo, o inusitado e o desconhecido. Além disso, conforme Vygotsky (1989), não se deve esperar o conhecimento chegar à criança, e sim "empurrá-la" até ele. Neste sentido, a zona de desenvolvimento proximal é onde o mediador (professor) deve dar pistas e ajudar a criança a resolver os problemas apresentados em diferentes situações.

Schild (1999), coloca que a diversidade nas condições sociais de vida promove aprendizagens também diversas, e estas, por sua vez ativam diferentes processos de desenvolvimento. Sendo a vivência no meio humano, uma alternativa através de atividade cultural, na interação com os outros que desenvolverá na criança um novo e 
complexo sistema psicológico, ou seja, a elaboração das funções psicológicas superiores (percepção, memória, atenção, imaginação...).

Segundo Santini e Voser (2008), o professor em suas atividades de ensino devem ter conhecimento da forma em que se desenvolvem os processo de aprendizagem e portanto conhecer as vantagens e desvantagens dos métodos de ensino a serem aplicados. Trabalhos de revisão (Greco, 1998; Greco e Benda, 1998; Santini e Voser, 2008;) mostram que os métodos global, parcial e misto serviram de inspiração para muitas pesquisas e por muito tempo foram referenciados como métodos de ensino dos esportes na educação física escolar. Posteriormente, outros métodos foram surgindo, alguns destes como variações do próprio método, tais como global em serie de jogos, confrontação, conceito recreativo do jogo esportivo e série funcional de jogos, entre outros.

Diante do exposto, os métodos de ensino oportunizam a formação básica do aluno, cabendo ao professor aplicar o que melhor atende aos seus alunos no planejamento de suas aulas, considerando, por exemplo, os objetivos propostos, a faixa etária dos alunos e o conteúdo a ser trabalhado.

Para Bayer (1994), existem duas correntes pedagógicas de ensino para os jogos esportivos coletivos: uma utiliza os métodos tradicionais, decompondo os elementos que constituem o esporte em partes. Assim a memorização e a repetição permitem moldar a criança e o adolescente ao modelo já consagrado para o adulto; a outra corrente destaca os métodos ativos, que levam em conta os interesses dos jovens e que, a partir de situações vivenciadas, iniciativa, imaginação e reflexão possam favorecer a aquisição de um saber adaptado às situações causadas pela imprevisibilidade. Este método (tradicionais) não permite ao aluno criar sua identidade, sua aproximação gradativa a esse modelo ideal, por outro lado, favorece que o professor tenha um maior controle da aula, somente o professor é o "proprietário" do conhecimento. Quando o ensino é realizado de forma a estimular a imaginação dos alunos, o professor encontra maior dificuldade em manter 0 controle da aula, sendo este um dos motivos pelos quais a primeira corrente é classificada como tradicional, e muito utilizada até hoje.

Garganta (1998) aponta duas formas tradicionais de ensino dos esportes coletivos, a forma centrada na técnica e a forma centrada no jogo formal. Na primeira, como o próprio nome sugere, ocorre a decomposição da modalidade hierarquicamente em elementos técnicos, gerando ações de jogo mecanizadas e pouco criativas, comportamentos estereotipados e problemas na compreensão da dinâmica do jogo, assim como ocorre na aplicação do método analítico. Na forma centrada no jogo formal, como ocorre no método global há prevalência quase exclusiva deste tipo de jogo, não havendo a decomposição em movimentos técnicos para seu ensino.

Segundo Greco (1999), contrariamente a estas correntes, os modelos de ensino-aprendizagem fundamentados em concepções do desenvolvimento da capacidade tática possibilitam que os praticantes utilizem de forma inteligente os elementos técnicos necessários à solução das diferentes situações de jogo, sugerindo, para isto, a utilização de uma metodologia situacional.

A metodologia situacional é constituída por formas próprias de condutas, onde a criança deve adquirir uma capacidade geral do jogo. Estes jogos devem ser apresentados de forma que os praticantes vivenciem situações o mais próximo possível da realidade do jogo, (KRÖGER \& ROTH, 2002). Definida como uma das novas correntes metodológicas, a metodologia situacional caracterizada como uma opção metodológica ativa, enfatiza o desenvolvimento da compreensão tática e dos processos cognitivos subjacentes à tomada de decisão procurando evitar que os praticantes sejam condicionados a um desgastante processo de ensino da técnica e a uma especialização precoce na modalidade, excluindo a oportunidade de desenvolver e promover uma cultura esportiva apoiada na diversidade. Ao mesmo tempo, o método visa oportunizar ao aluno uma construção do conhecimento tático-técnico, (GIACOMINI, 2007).

Esse conhecimento, relacionado com a compreensão tática e ligado diretamente ao modo como um aluno concebe e percebe 0 jogo (GARGANTA, 2004), pode ser considerado e analisado com base em dois conteúdos cognitivos importantes, denominados conhecimento declarativo e processual.

De acordo com Housner e French apud Giacomini (2007), o conhecimento tático no esporte está baseado no conhecimento declarativo e processual, evidenciando que os alunos empregam diferentes processos cognitivos nas situações de jogo. $O$ conhecimento declarativo no esporte, segundo Thomas et al. apud Giacomini (2007), refere-se ao conhecimento do regulamento, das posições dos 
alunos e estratégias básicas de defesa e ataque (saber o que fazer).

Segundo Kröger e Roth (2002), o
conhecimento processual corresponde à
capacidade do aluno de "saber como e quando"
fazer tarefas complexas, selecionando as ações
motoras mais adequadas dependendo da
situação de jogo.

Os jogos esportivos coletivos requerem que 0 aluno faça tarefas complexas a todo instante, portanto o conhecimento processual é de suma relevância para as aulas de Educação Física.

Segundo Moreira (2007), os jogos esportivos coletivos são conteúdos predominantes nas aulas de Educação Física, no qual seu ensino se dá em um ambiente imprevisível variável e de constante mudança. De acordo com Greco (1995), é constantemente requerida a capacidade cognitiva, por exemplo, a percepção, pensamento, inteligência, tomada de decisão.

Acredita-se que os jogos esportivos coletivos mais comuns nas aulas de Educação Física escolar sejam: futsal, handebol, basquetebol e voleibol.

Tomar uma decisão tática nos esportes significa que o aluno deve concluir: o que fazer, porque fazer, como fazer, quando fazer, onde fazer, ou seja, com qual gesto técnico será realizada a tomada de decisão necessária para solucionar a tarefa ou problema que o aluno se defronta na situação.

Considerando o exposto, pode-se observar que os métodos de ensino-aprendizagem dos jogos esportivos coletivos empregados nas escolas devem-se constituir como importantes objetos de estudo tanto para a Educação Física Escolar bem como as Ciências do Desporto.

Sendo os jogos situacionais atividades que se propõem a desenvolver a criatividade e a inteligência, torna-se relevante verificar seus efeitos sobre o conhecimento tático processual dos alunos e o professor deve utilizar os jogos situacionais constantemente.

Segundo Santini e Voser (2008), o professor que leva a sério o que faz, que alia sua competência técnica ao compromisso de ensinar, que desperta a criatividade e conduz os alunos à reflexão, certamente não terá alunos desinteressados ou desanimados, mesmo porque, o professor leva grande vantagem sobre os demais componentes curriculares, pois a Educação Física por si só é uma prática motivadora.
Neste sentido o objetivo do presente estudo consiste em verificar a influência da aplicação de jogos situacionais, sobre os níveis de Conhecimento Tático Processual em escolares na modalidade de handebol.

\section{Métodos}

A amostra foi intencional, composta de trinta e cinco $(n=35)$ alunos estudantes de uma escola pública da cidade de Pelotas, da quinta série do ensino fundamental, na faixa etária de 10 a 12 anos, as turmas escolhidas foram quinta $A$ e quinta B. Segundo Triviños (1987), a amostra intencional requer a consideração de condições essenciais para o esclarecimento do assunto em foco, de acordo com os atributos que 0 pesquisador pretende conhecer (sujeitos que sejam essenciais sob o ponto de vista do pesquisador, tempo dos indivíduos para as entrevistas, facilidade para se encontrar as pessoas, etc.).

A escolha dos grupos como experimental e de controle se deu por sorteio. Outro critério utilizado na escolha da amostra foi determinado pela aplicação do Teste de Conhecimento Tático Processual (KORA), ) desenvolvido por Memmert, já aplicado em trabalhos de investigação no Brasil, (GIACOMINI, 2007; MORALES, 2007; MOREIRA 2005). O teste apresenta índices de validade e fidedignidade para sujeitos de 06 a 12 anos de idade, sendo que os alunos desta faixa etária encontram-se na quinta série do ensino fundamental, na qual se aplicou o processo de ensino-aprendizagem objeto deste estudo.

Foi realizado estudo piloto para familiarização da pesquisadora com o teste KORA.

A experiência prévia dos participantes do estudo na modalidade de handebol dentro da escola foi de $28,57 \%$, e fora da escola foi nula. Dentre os alunos $34,28 \%$ relataram participar de esportes fora da escola, entre eles: $83,33 \%$ futebol, 8,3\% Wind surf e 8,3\% corrida.

É importante ressaltar que $34,28 \%$ da amostra apresentaram uma determinada experiência motora em outras modalidades esportivas.

Pode-se observar a partir do questionário de caracterização da amostra aplicado que 100\% dos alunos praticam atividades esportivas recreativas com amigos na rua: futebol $66,33 \%$, voleibol $12,11 \%$, caçador $8,3 \%$, caminhada na praia $7,6 \%$, taco $3,5 \%$ e $2,16 \%$ bolinha de gude, porém esta prática não é constante.

A amostra foi dividida em dois grupos: $\mathrm{G} 1=$ jogos situacionais - 17 alunos; $G 2=$ grupo controle (método misto) - 18 alunos. 
No G1, foi apresentada uma metodologia com jogos situacionais na escola. Estudos na área mostram que com menos de 12 aulas não se observam melhoras nos processos de aprendizagem (GRIFFIN; OSLIN; MITCHELL, 1995; STUART; THORPE, 1997 apud MORALES, 2007) e, portanto neste estudo o processo de observação foi realizado durante 18 aulas de Educação Física. A delimitação do método de ensino se apóia na proposta de Stefanello (1999) já aplicada em outros estudos no Brasil, (MORALES, 2007; GIACOMINI, 2007; MOREIRA, 2005), sendo que para tal realizou-se a analise do tempo, e das características das atividades ofertadas pelos professores nas aulas.

Para analisar a influencia do método foi aplicado o teste de CTP - KORA (MEMMERT, 2002) em dois momentos, no pré-teste e pósteste a fim de verificar possíveis existências de variações nos níveis de CTP nos dois grupos. $O$ teste foi filmado e entregue para análise dos peritos do Centro de Estudos Cognição e Ação (CECA), da Escola de Educação Física, Fisioterapia e Terapia Ocupacional (EEFFTO) da Universidade Federal de Minas Gerais (UFMG).

As aulas, com duração de 35 minutos foram filmadas e armazenadas também em mídia eletrônica (DVD), de forma que dois avaliadores realizaram a análise das atividades e caracterizaram o método.

A pesquisa foi aprovada pelo Comitê de Ética e Pesquisa da ESEF - UFPEL (Processo 002/2008), bem como foram obtidas as respectivas assinaturas dos termos de consentimento livre e esclarecido pelos participantes.

Os conteúdos das aulas para o grupo intervenção (jogos situacionais) foram retirados do livro Escola da Bola (Kroger e Roth, 2002) e do livro Iniciação Esportiva Universal I (Greco e Benda, 1998) e do livro Fundamentos Pedagógicos para o Programa Segundo Tempo (Greco e Silva, 2008).

O conteúdo do grupo controle foi o handebol, e a metodologia empregada foi definida pela professora da turma utilizando o método misto: parcial/global.

A categorização do método de ensino foi realizada por dois avaliadores que apresentaram um índice de 0,85 (inter-avaliador) e 0,82 (intraavaliador), em uma escala que varia de 0 a 1 , mostrando alta fidedignidade nos dados.

A avaliação do comportamento tático processual, foi realizada conforme os parâmetros
"Oferecer-se e Orientar-se" (O.O.) e "Reconhecer Espaços" (R.E.), que são definidos, respectivamente, segundo Kröger e Roth (2002), como "a qualidade do sujeito de, a todo o instante, obter uma posição ótima para receber a bola" e; "a qualidade necessária ao aluno para que ele perceba as possibilidades de se chegar ao objetivo". Assim, no teste de se oferecer se orientar (O.O.) avalia-se o comportamento do aluno sem bola, e no teste de reconhecer espaços avalia-se o comportamento do aluno com bola.

Como segundo procedimento de avaliação utilizou-se 0 protocolo de categorização das atividades oferecidas pelo professor em cada grupo. Definiu-se o protocolo de Stefanello (1999) adaptado por Saad (2002) para o futsal e modificado pelo CECA da UFMG para o handebol.

Para análise estatística dos dados foi utilizado o programa SPSS 13 , com estatística descritiva (soma, mediana e moda), Wilcoxon, (pareado: para avaliar a variabilidade dentro do mesmo grupo e o não-pareado para avaliar a variabilidade entre os grupos), e uma análise de delta (pré e pós), para posterior análise descritiva por meio da freqüência percentual.

Optou-se por utilizar o teste de Wilcoxon devido ao tamanho de amostra em ambos grupos ser inferior a 25, bem como pela forma da distribuição da população, que levaram a decisão de uma avaliação através de um teste nãoparamétrico.

Calculou-se o coeficiente alfa (alfa de conbrach), para se observar a consistência interna dos peritos na avaliação da bateria de testes KORA, nos parâmetros táticos oferecer-se orientar-se e reconhecer espaços, a qual mostrou consistência interna, no grupo 1 , com média de valores 0,86 e no grupo 2 , com média de valores de 0,91 , em uma escala de 0 a 1 , mostrando alta fidedignidade dos avaliadores.

Para se identificar diferenças significativas nos efeitos dos métodos aplicados para desenvolver o CTP utilizou-se o nível de significância p 0,05.

Para confirmar as diferenças entre os dois grupos na utilização dos métodos de ensino identificados, procedeu-se a análise dos dados contidos no protocolo formulado por Stefanello (data) nos quesitos características das tarefas, portanto, calculou-se o qui-quadrado $\left(X^{2}\right)$ nos parâmetros tarefas: aquisição da técnica $X^{2}=$ $32,67$ ( $p<0,05)$, fixação e diversificação da técnica $X^{2}=10,89(p<0,05)$, aplicação da técnica $X^{2}=$ $25,0(p<0,05)$ e competição $X^{2}=38,9(p<0,05)$. 
Também foram analisadas as condições da tarefa: fundamento individual $X^{2}=36,0(p<0,05)$, combinação de fundamentos $X^{2}=19,89(p<0,05)$, complexo de jogo I $X^{2}=12,0(p<0,05)$ e jogo $X^{2}=$ $28,0(p<0,05)$.

\section{Resultados e Discussão}

Foram estruturadas e categorizadas dezoito (18) aulas em cada grupo, ou seja, um total de 36 aulas. O grupo 1 apresentou um tempo total de 619,59 minutos e o grupo 2 destinou um tempo total de 577,42 minutos, ambos desenvolvidos nas 18 aulas observadas conforme se descreve na tabela 1 a seguir.

Tabela 1. Distribuição do tempo e porcentagem nos diferentes segmentos da aula.

\begin{tabular}{l|crrrr}
\hline \multirow{2}{*}{ SEGMENTO DO TREINO } & \multicolumn{2}{|c}{ GRUPO 1 (situacional) } & \multicolumn{2}{c}{ GRUPO 2 (misto) } \\
\cline { 2 - 5 } & Minutos & \multicolumn{1}{c}{$\%$} & Minutos & \multicolumn{1}{c}{$\%$} \\
\hline Conversa & 49,23 & $7,95 \%$ & 62,73 & $10,86 \%$ \\
Técnico & 0 & $0 \%$ & 252,13 & $43,67 \%$ \\
Tático-técnico & 397,33 & $64,12 \%$ & 0 & $0 \%$ \\
Coletivo & 173,03 & $27,93 \%$ & 262,56 & $45,47 \%$ \\
TOTAL/minutos & $\mathbf{6 1 9 , 5 9}$ & $\mathbf{1 0 0} \%$ & $\mathbf{5 7 7 , 4 2}$ & $\mathbf{1 0 0 \%}$ \\
\hline
\end{tabular}

Foram identificados quatro (4) tipos de segmentos diferentes das aulas correspondentes aos parâmetros: conversa com o professor, treinamento técnico, treinamento tático-técnico e jogo. Verificou-se o tempo empregado pela professora para cada um desses segmentos (Tabla 1). Optou-se neste espaço por apresentar estes dados somente na formatação da sua freqüência percentual.

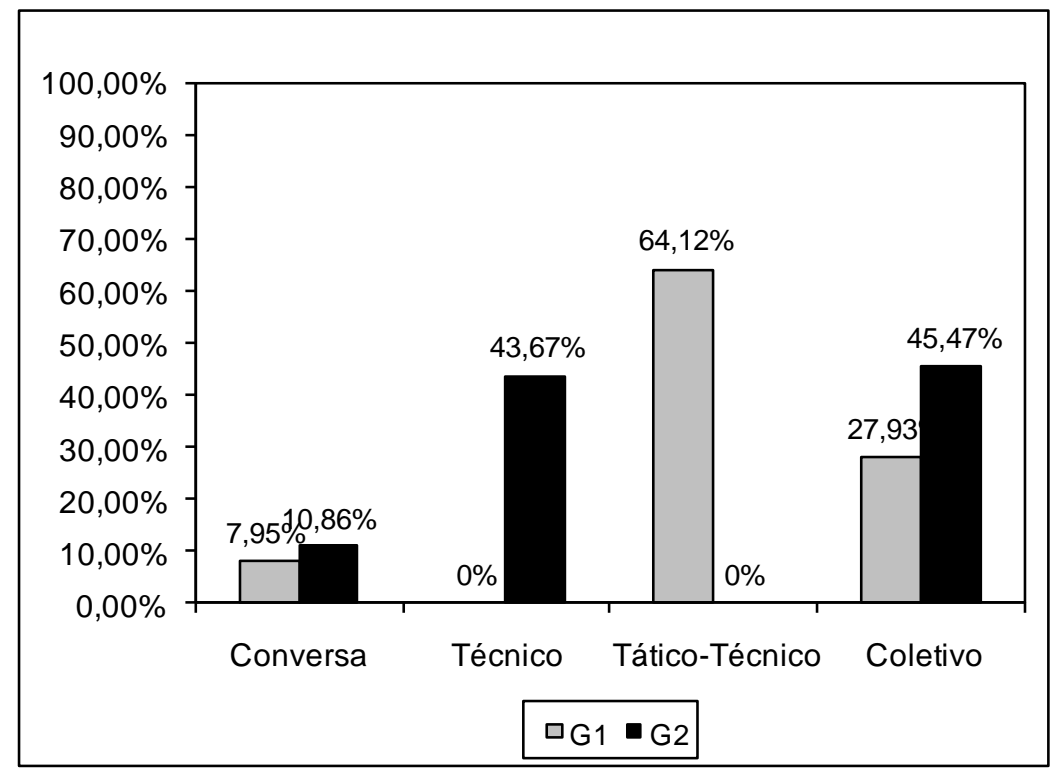

Gráfico 1. Comparação da distribuição dos segmentos das aulas nos grupos 1 (método situacional) e

Observa-se no gráfico 1 que o grupo 1 , destinou $64,12 \%$ do tempo total ao segmento tático-técnico, e nenhum momento ao segmento técnico nas 18 aulas. Isto, portanto caracteriza o método de ensino como situacional, ou seja, centrado no desenvolvimento da capacidade tática através de situações de jogo.

No grupo 2, verifica-se que $43,67 \%$ foi destinado ao segmento técnico e $45,47 \%$ ao segmento coletivo (jogo), sendo possível descrevê-lo como um método misto (parcial e global).

Segundo Morales (2007), a ênfase dada por cada equipe a determinado segmento da aula oportuniza relacionar temporalmente com o método de ensino-aprendizagem adotado.

Verifica-se que no grupo 1 (jogos situacionais), nas 18 aulas de um total de 619,59 minutos, 
destinou-se 397,33 minutos $(64,12 \%)$ enfatizando o segmento tático-técnico e 173,03 minutos (27,93\%) ao jogo coletivo. Já o Grupo 2 (controle) utilizou-se predominantemente o método misto (analítico + global), já que nas 18 aulas de um total de 577,42 minutos, destinou-se 262,56 minutos ao jogo coletivo $(45,47 \%$ ) e 252,13 minutos $(43,67 \%)$ ao segmento técnico específico, possibilitando portanto diferenciar os métodos e os dois grupos.

Salienta-se que no grupo 1 (método situacional), o tempo destinado ao jogo coletivo é relacionado com $O$ desenvolvimento das capacidades táticas (CT) e dentro destas foram apresentados os conteúdos relacionados com os jogos situacionais onde o jogo coletivo (JC) é um de seus elementos.

Outro aspecto importante é que no grupo 1 (jogos situacionais), houve uma considerável utilização de atividades tático-técnicas através das estruturas funcionais - jogos em situações didaticamente organizadas onde se apresenta o jogo em constelações menores que $o$ jogo formal $(1 X 1,2 X 2,2 \times 2+1$,etc.) - portanto aumenta a quantidade de ações que cada participante realiza. Essas estruturas foram complementadas pelos jogos para desenvolver a inteligência tática demonstrando novamente a predominância do método situacional demonstrando novamente a predominância do método situacional.

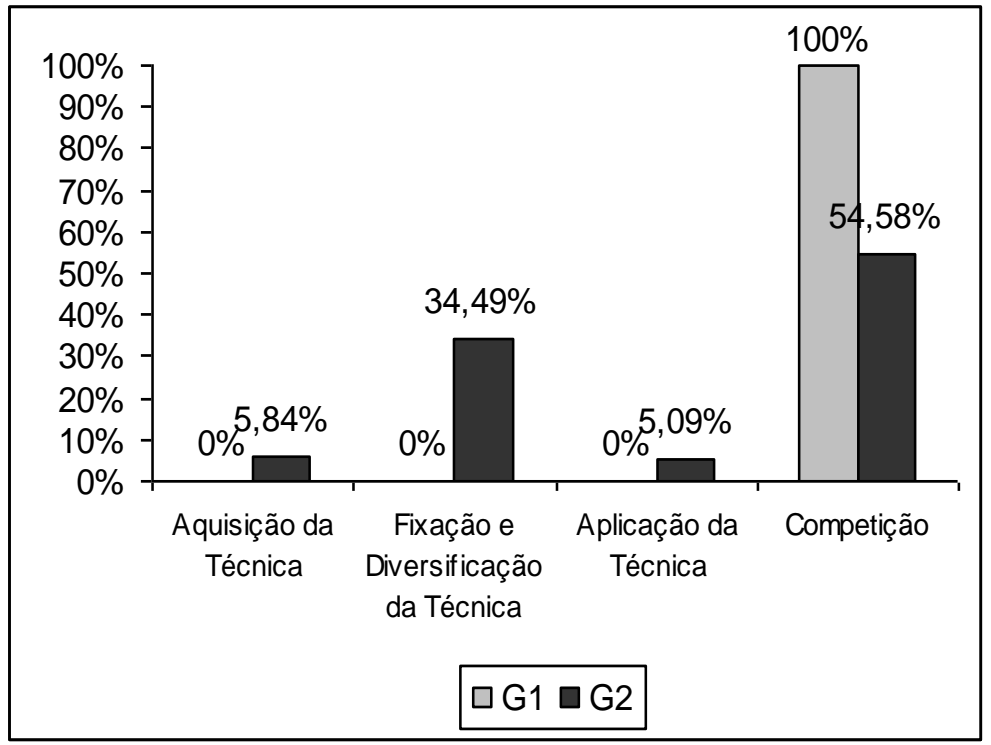

Gráfico 2. Comparação das tarefas nas aulas dos grupos 1 e 2 em porcentagem.

Percebe-se que o grupo 1 (jogos situacionais), destinou $100 \%$ das tarefas de competição, isto porque segundo Greco e Benda (1998), "jogar se aprende jogando". Os conteúdos das aulas estavam programados através da metodologia situacional, entendendo-se esta competição na forma de jogos (variável do estudo) e não no modelo de competição do adulto.

Já o grupo 2 (controle), apresentou uma freqüência percentual de $5,84 \%$ na utilização de tarefas de aquisição da técnica, $34,49 \%$ em tarefas de fixação e diversificação da técnica, $5,09 \%$ em tarefas de aplicação da técnica e $54,58 \%$ em tarefas de competição.

No grupo 2 (controle), é evidenciada a execução de exercícios que objetivam o aperfeiçoamento da técnica, que se afastam da situação real do jogo. A ênfase observada nas tarefas de fixação da técnica esta relacionada com a freqüência da utilização dos fundamentos individuais e de combinação de fundamentos.

Percebe-se no gráfico 3 , que o grupo 1 (método situacional) utilizou com maior freqüência atividades que são constitutivas do parâmetro complexo de jogo 1 (15,55\%), jogos para desenvolver a inteligência tática $(54,12 \%)$ e jogo $(30,33 \%)$, dando ênfase as tarefas relacionadas com as capacidades táticas, confirmando a utilização predominante do método situacional.

Já no grupo 2 (controle), utilizou uma maior freqüência nos parâmetros fundamento individual $(18,89 \%)$ e combinação de fundamentos $(30,11 \%)$, caracterizando o método parcial e no parâmetro jogo (51\%) caracterizando o método global, portanto 0 grupo 2 (controle) é denominado de método misto (parcial + global). 


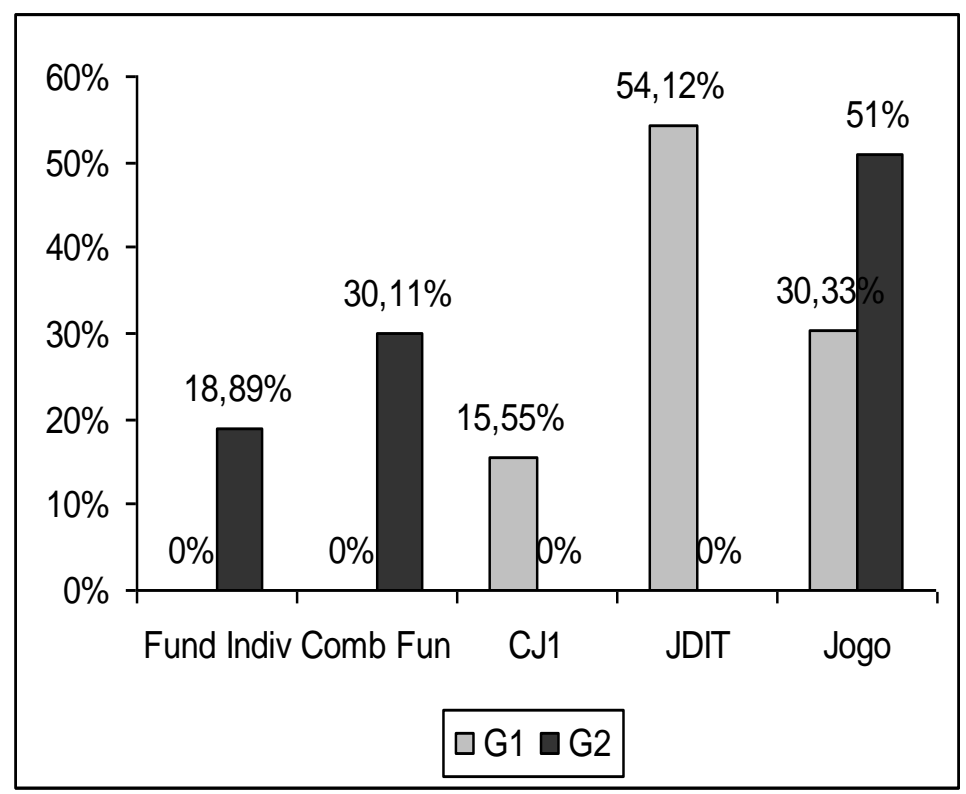

Gráfico 3. Comparação da distribuição das condições das tarefas realizadas nas aulas dos grupos 1 e 2 em porcentagem.

As constatações encontradas no estudo permitem confirmar as metodologias empregadas nos dois grupos. O grupo 1 (método situacional) apresentou uma metodologia centrada no ensino da tática com ênfase no método situacional. Já no grupo 2 (controle), os resultados permitem concluir uma metodologia centrada no ensino da técnica (parcial) e no jogo (global), predominando o método misto.

$\mathrm{Na}$ análise dos resultados obtidos na aplicação do teste de conhecimento tático processual KORA: oferecer-se orientar-se e reconhecer espaços nos pré-testes e pós-testes utilizou-se a soma total de pontos obtidos pelos grupos 1 e 2 .

Utilizou-se a soma, a mediana e a moda dos pontos obtidos nos testes com o propósito de verificar o valor mais comum entre os grupos e deste modo utilizar um parâmetro qualitativo na avaliação com o uso da estatística descritiva.

Tabela 2. Resultado do pré-teste e do pós-teste para conhecimento tático processual KORA: OO convergente (inteligência).

\begin{tabular}{l|c|cc|c}
\hline \multirow{2}{*}{} & \multicolumn{2}{|c}{$\begin{array}{c}\text { GRUPO 1 } \\
\text { (situacional) }\end{array}$} & \multicolumn{2}{c}{ GRUPO 2 (misto) } \\
\cline { 2 - 5 } & Pré-teste & Pós-teste & $\begin{array}{c}\text { Pré- } \\
\text { teste }\end{array}$ & $\begin{array}{r}\text { Pós- } \\
\text { teste }\end{array}$ \\
\hline Pontos & 73 & 91 & 89 & 71 \\
Mediana & 4 & 5 & 5 & 3 \\
Moda & 4 & 5 & 5 & 3 \\
Valor $p$ & & 0,04 & & 0,01 \\
\hline
\end{tabular}

De acordo com a tabela 2 verifica-se que para o conhecimento tático processual no parâmetro oferecer-se orientar-se convergente (inteligência), o grupo 1 apresentou aumento nos escores e o grupo 2 apresentou diminuição nos escores. Os dois grupos apresentaram diferenças significativas entre os escores obtidos entre o préteste e pós-teste, no entanto no grupo1 $(p=0,04)$ esta diferença mostra uma melhora na aprendizagem e no grupo $2 \quad(p=0,01)$, esta diferença confirma que não houve aquisição do conhecimento tático processual.

A "piora" no grupo 2 pode ter ocorrido em função dos alunos, na escola, estarem acostumados a praticar atividades coletivas abertas, especialmente futebol. O que conflita com a aprendizagem de outra modalidade no caso com as mãos.

No grupo 1, considerado método situacional, observa-se que houve uma melhora nos escores obtidos no pré-teste (73) para o pós-teste (91) com uma diferença de 18 pontos.

A mediana e a moda apresentaram um valor de 04 pontos no pré-teste. Segundo o gabarito do KORA: OO convergente (validado por MEMMERT, 2002) este valor significa um comportamento tático em que "o aluno não tem, quase nunca, procurado a posição ótima de forma a oferecer ao portador da bola a opção de passe, no entanto a situação de jogo era difícil' (escore 4 OO convergente).

No pós-teste o valor da moda e da mediana foi de 05 pontos mostrando que: "o aluno tem de forma irregular procurado a posição ótima, ele têm oferecido ao portador da bola quase sempre a 
possibilidade de realizar o passe, a situação não era difícil' (escore 500 convergente).

Esses valores conforme o gabarito KORA: OO convergente apresentam um aumento no nível de inteligência (de 04 para 05 pontos), no momento de mostrar a resposta mais adequada na procura de espaços livres para receber a bola.

No grupo 2, denominado método misto (parcial + global), apresenta um valor p 0,01 , evidenciando diferença significativa do pré-teste para o pré-teste.

Não houve melhora nos escores. Ao contrário, no pré-teste teve um total de pontos obtidos de 89 e no pós-teste diminui para 71 pontos, determinando uma diferença de 18 pontos.

O valor da moda e da mediana no pré-teste foi de 05 pontos que conforme o gabarito de KORA: OO convergente (inteligência) significa "O aluno tem de forma irregular procurado a posição ótima, ele têm oferecido ao portador da bola quase sempre a possibilidade de realizar o passe, a situação não era difícil", (escore 5 O० convergente), no entanto no pós-teste diminui para 03 pontos onde "o aluno, apesar de estar em uma posição fácil, não procura quase nunca uma posição ótima para oferecer ao colega portador da bola a opção do passe", (escore 300 convegente).

Os resultados obtidos pelos grupos 1 (situacional) e 2 (misto- parcial/global), no parâmetro oferecer-se orientar-se, no que se refere à inteligência (pensamento convergente), mostra uma influência das atividades planejadas nas aulas de educação física.

Verifica-se a importância do uso do método situacional, baseado na solução de problemas por meio de situações do contexto real de jogo.

No grupo 1 , onde foi estimulado a realização de atividades centradas na tática, os alunos melhoraram seu comportamento tático, e no grupo 2, onde empregou-se o método misto (parcial + global), os alunos não progrediram no seu comportamento tático, pelo contrário, demonstraram decréscimo nos escores.

Portanto, confirmam-se os resultados encontrados em estudos anteriores (CORRÊA et al 2004; MOREIRA, 2005; MORALES, 2007; COLLET, 2007; MENDES, 2006), onde se apresentaram diferenças significativas na aprendizagem nos métodos centrados na tática quando comparados com outros métodos de ensino-aprendizagem.
Tabela 3. Resultado do pré-teste e do pós-teste para conhecimento tático processual KORA: OO divergente (criatividade).

\begin{tabular}{l|r|rr|r}
\hline \multirow{2}{*}{} & \multicolumn{2}{|c}{$\begin{array}{c}\text { GRUPO 1 } \\
\text { (situacional) }\end{array}$} \\
\cline { 2 - 5 } & Pré-test & Pós-teste & $\begin{array}{r}\text { Pré- } \\
\text { teste }\end{array}$ & $\begin{array}{r}\text { Pós- } \\
\text { teste }\end{array}$ \\
& & 69 & 65 & 52 \\
Pontos & 53 & 69 & 3 & 2 \\
Mediana & 3 & 4 & 3 & 2 \\
Moda & 3 & 0,01 & & 0,02 \\
Valor $p$ & & & & \\
\hline
\end{tabular}

Na tabela 3, confirma-se uma melhora de 16 pontos no total obtido no grupo 1 do pré-teste (53) para o pós-teste (69) o que representa uma diferença significativa no parâmetro tático oferecer-se orientar-se divergente (criatividade), nos escores do pré-teste para o pós-teste nas duas equipes.

A mediana e a moda apresentaram no préteste um valor de 03 pontos que segundo 0 gabarito KORA: OO divergente (validado por MEMMERT, 2002) significa "o aluno mostra soluções padrões que aparecem freqüentemente, as procuras temporais de ótimas posições tiveram pouca novidade", (escore 3 OO divergente), no pós-teste o valor da mediana e da moda foi de 4 pontos onde "o aluno mostra uma solução diferente e fora do padrão, as procuras temporais tem um pouco de novidade", (escore $4 \mathrm{OO}$ divergente).

Esses valores indicam um aumento no nível da criatividade (de 03 para 04 pontos), no momento de apresentar novidade na procura de posições adequadas e espaços livres para receber a bola.

No grupo 2, (método misto), houve uma diminuição nos escores obtidos, que no pré-teste foram de 65 pontos e no pós-teste de 52 pontos com uma diferença negativa de 13 pontos. Observa-se uma diferença significativa $(p=0,02)$, do pré-teste para o pós-teste.

A mediana e a moda apresentaram no préteste um valor de 03 pontos que segundo 0 gabarito KORA: OO divergente (validado por MEMMERT, 2002), significa "o aluno mostra soluções padrões que aparecem freqüentemente, 
as procuras temporais de ótimas posições tiveram pouca novidade", (escore 3 OO divergente), no pós-teste o valor da mediana e da moda foi de 2 pontos onde "o aluno não mostra soluções diferentes somente no padrão, as procuras temporais tem um pouco de novidade", (escore 2 OO divergente).

Portanto, segundo Greco e Silva (2006), a forma mais adequada de contribuir no desenvolvimento da criatividade do aluno é por meio de atividades que requisitem um amplo volume e distribuição da atenção, a utilização do pensamento divergente na geração de idéias e do pensamento convergente na escolha da melhor alternativa para se encontrar soluções táticas adequadas ás exigências situacionais, que a própria competição e o próprio jogo impõe ao participante.

Tabela 4. Resultado do pré-teste e do pós-teste para conhecimento tático processual KORA: RE convergente (inteligência).

\begin{tabular}{c|r|rr|r}
\hline \multirow{2}{*}{} & \multicolumn{2}{|c}{$\begin{array}{c}\text { GRUPO 1 } \\
\text { (situacional) }\end{array}$} \\
\cline { 2 - 5 } & Pré-teste & Pós-teste & $\begin{array}{r}\text { Pré- } \\
\text { teste }\end{array}$ & $\begin{array}{r}\text { Pós- } \\
\text { teste }\end{array}$ \\
\hline Pontos & 72 & 89 & 94 & 66 \\
Mediana & 3 & 5 & 5 & 3 \\
Moda & 3 & 5 & 5 & 3 \\
Valor $p$ & & 0,01 & & $<0,001$ \\
\hline
\end{tabular}

No grupo 1 , o total de pontos obtidos no préteste foi 72 e no pós-teste foi de 89 , com uma diferença de 17 pontos $(p=0,01)$.

A mediana e a moda apresentaram um valor de 03 pontos no pré-teste determinando um comportamento tático que segundo o gabarito do KORA: RE convergente (validado por MEMMERT, 2002), "o aluno apresenta várias decisões erradas, mas não cometeu erros graves em situações difíceis", (escore 3 RE divergente), no pós-teste apresentaram um valor de 05 pontos onde "o aluno apresenta várias situações críticas, mas nenhuma errada, e as soluções eram de dificuldade média", (escore 5 re convergente).

Esses valores, segundo o gabarito do KORA: $R E$ convergente indicam um adequado nível de qualidade nas soluções propostas, confirmando a aquisição do conhecimento tático, devido às atividades desenvolvidas nas aulas.

No grupo 2, o total de pontos obtidos no préteste foi de 94 e no pós-teste de 66 pontos com uma diferença negativa de 28 pontos.

A mediana e a moda apresentaram no préteste um valor de 05 pontos onde "o aluno apresenta várias situações críticas, mas nenhuma errada, e as soluções eram de dificuldade média" (escore $5 \mathrm{RE}$ convergente). E no pós-teste esse valor baixou para 03 pontos onde "o aluno apresenta várias decisões erradas, mas não cometeu erros graves em situações difíceis" (escore 3 RE convergente).

Acredita-se que a estruturação das aulas conforme os dois métodos determinou os resultados. No grupo 1, que trabalhou com atividades que deram ênfase ao segmento táticotécnico, os alunos aumentaram os escores do pré-teste para o pós-teste e no grupo 2, diminuíram os valores absolutos em pontos.

Tabela 5. Resultado do pré-teste e do pós-teste para conhecimento tático processual KORA: RE divergente (criatividade).

\begin{tabular}{l|c|cc|c}
\hline \multirow{2}{*}{} & \multicolumn{3}{|c}{$\begin{array}{c}\text { GRUPO 1 } \\
\text { (situacional) }\end{array}$} \\
\cline { 2 - 5 } & Pré-teste & Pós-teste & $\begin{array}{r}\text { Pré- } \\
\text { teste }\end{array}$ & $\begin{array}{r}\text { Pós- } \\
\text { teste }\end{array}$ \\
\hline Pontos & 55 & 67 & 71 & 45 \\
Mediana & 3 & 4 & 3 & 2 \\
Moda & 3 & 4 & 3 & 2 \\
Valor $p$ & & 0,07 & & 0,51 \\
\hline
\end{tabular}

$\mathrm{Na}$ tabela 5 , observa-se que em ambos os grupos não houve diferença significativa do préteste para o pós-teste no parâmetro reconhecer espaços divergente (criatividade), apresentando um valor $p>0,05$.

No grupo 1 , o total de pontos obtidos no préteste foi de 55 pontos e no pós-teste foi de 67 pontos com uma diferença de 12 pontos.

A mediana e a moda apresentaram um valor de 03 pontos no pré-teste que segundo o gabarito do KORA: RE divergente "o aluno tem apresentado geralmente soluções padrão, as que já foram oferecidas. As descobertas dos espaços e dos passes foram com um pouco de novidade" (escore 3 RE divergente), no pós-teste aumentou 
para 04 pontos, onde "o aluno mostra duas alternativas de soluções diferentes, não sendo do tipo padrão, mas que apareceram freqüentemente no jogo, as descobertas dos espaços livres foram com novidades" (escore 4 RE divergente).

No grupo 2, o valor de pontos obtidos no préteste foi de 71 e no pós-teste de $45 \mathrm{com}$ uma diferença negativa de 26 pontos.

O valor da mediana e da moda foi de 03 pontos que segundo o gabarito do KORA: RE divergente, "o aluno tem apresentado geralmente soluções padrão, as que já foram oferecidas. As descobertas dos espaços e dos passes foram com um pouco de novidade" (escore 3 RE divergente), e diminui para 02 pontos, onde " 0 aluno tem apresentado somente soluções padrão, as que já foram oferecidas, as descobertas dos espaços e dos passes foram com pouca novidade" (escore 2 RE divergente).

Esses valores conforme o gabarito do KORA: RE divergente, indicam que no grupo 1 , onde se destinou a maior parte do tempo ao segmento tático, obteve aquisição do conhecimento tático (de 03 para 04 pontos), produto das atividades desenvolvidas nas aulas.

Pode-se afirmar que os alunos pertencentes ao grupo 1 (método situacional), apresentaram escores maiores na avaliação e análise dos parâmetros táticos oferecer-se orientar-se e reconhecer espaços. Confirmando uma evolução na aprendizagem por meio da aquisição de conhecimento tático processual.

A diferença entre os grupos é visível, no entanto, quando compara-se as médias dos dois grupos, a análise estatística mostra que em dois parâmetros (OO convergente no pós-teste e $\mathrm{OO}$ divergente no pré-teste) não há diferença estatisticamente significativa. Nos itens abaixo, verificam-se os valores dos " $p$ " em cada parâmetro analisado.

Conclui-se que os métodos investigados, ou seja, o método situacional e o grupo controle (método misto - analítico/global), são diferentes.

\section{Conclusão}

Verificou-se que no grupo 1 , o processo de ensino-aprendizagem-treinamento teve ênfase nas atividades que permitiram considerá-lo como método situacional. Essa afirmativa é sustentada pela quantidade de tempo destinado ao segmento tático-técnico $(64,12 \%)$ nas 18 aulas e pela freqüência na utilização de tarefas referentes aos parâmetros: CJ1 (15,55\%) e JDIT (54,12\%).

No grupo 2, verificou-se um processo de ensino-aprendizagem-treinamento com ênfase nas atividades que permitem considerá-lo como método misto (parcial-global). Sustentada pela quantidade de tempo ao parâmetro técnica $(43,67 \%)$ e jogo coletivo (45,47\%) nas 18 aulas e pela freqüência na utilização de tarefas referentes aos parâmetros: fundamento individual (18,89\%) e combinação de fundamentos (30,11\%).

Portanto, podemos afirmar que o grupo 1 apresentou um modelo de ensino-aprendizagemtreinamento centrado no desenvolvimento da capacidade tática, e o grupo 2 no método misto (analítico - capacidade técnica e global - jogo coletivo).

Confirma-se que o método situacional é eficaz na melhoria dos níveis de CTP em ambos parâmetros (OO, RE, Convergente e Divergente). Já o método analítico, juntamente com o global, não se mostrou eficaz para melhorar os níveis de CTP.

Cabe salientar que, no grupo 1, método situacional, os alunos mantinham-se motivados com as aulas e gostavam de participar das atividades propostas. No entanto, no grupo 2, método misto, os alunos mostravam resistência para prática das atividades e reclamavam bastante da metodologia empregada, o que pode ter contribuído para os resultados encontrados.

Sugere-se que sejam realizados estudos comparando resultados de gêneros diferentes, considerando que na faixa etária recomendada para aplicação do teste KORA (6 a 12 anos), as variáveis motoras se manifestam de formas diferentes.

\section{Referências}

BAYER, C. O ensino dos deportos colectivos. Lisboa: Dinalivros, 1994.

CORRÊA, U. C.; SILVA, A. S.; PAROLI, R. Efeitos de diferentes métodos de ensino na aprendizagem do futebol de salão. Revista Motriz, Rio Claro, v. 10, p. 79-88, 2004.

FREIRE, J. B. Educação de corpo inteiro: teoria e prática da Educação Física. São Paulo: Scipione, 1997.

GARGANTA, J. Para uma teoria dos jogos desportivos colectivos. In: GRAÇA, A.; OLIVEIRA, 
J. (Org.). O ensino dos jogos desportivos. V. 3. ed. Porto: Universidade do Porto, 1998.

GARGANTA, J. A formação estratégico - tática nos jogos desportivos de oposição e cooperação. In: GAYA, A.; MARQUES, A.; TANI, G. (Org.) Desporto para crianças e jovens. Razões e finalidades. Porto Alegre: Editora UFRGS, 2004. p. 217-233.

GIACOMINI, D. S. Conhecimento Tático Declarativo e Processual no Futebol: estudo comparativo entre alunos de diferentes categorias e posições. Dissertação de Mestrado, EEFFTO, UFMG, 2007.

GRECO, P.J.; BENDA, R. N. (Org.) Iniciação Esportiva Universal: da aprendizagem motora ao treinamento técnico. Belo Horizonte: UFMG. V. 1, p. 230, 1998.

GRECO, P. J.; SILVA, S.A. A metodologia do ensino dos esportes no marco do programa segundo tempo. In: OLIVEIRA, A.A.D.; PERIM, G.L. Fundamentos Pedagógicos para o Programa Segundo Tempo. Brasília: Ministério dos Esportes; Porto Alegre: UFRGS, 2008.

KRÖGER, C.; ROTH, K. Escola da bola: um $A B C$ para iniciantes nos jogos esportivos. São Paulo: Phorte, 2002.

MEMMERT, D. Diagnostik Taktischer Leistungskomponenten: Spieltestsituationen und Konzeptorientierte Expertenratings. Tese (Doutorado) - Universidade de Heidelberg, Heidelberg, 2002.

MORALES, J. C. P. Processo de EnsinoAprendizagem-Treinamento no Basquetebol: influência no conhecimento tático processual. Dissertação de Mestrado, EEFFTO, UFMG, 2007.

MOREIRA, V. J. P. Aquisição do conhecimento tático conforme os processos metodológicos do Ensino-Aprendizagem-Treinamento (E-A-T): à exemplo no futsal. Dissertação de Mestrado, EEFFTO, UFMG, 2005.

SAAD, M. A. Estruturação das sessões de treinamento técnico-tático nos escalões de formação do Futsal. Dissertação de Mestrado. CEFD, UFSC, Florianópolis, 2002.

SANTINI, J.; VOSER, R. C. Ensino dos esportes coletivos: uma abordagem recreativa. Canoas: Editora Ulbra, 2008.

SCHILD, J. F. G. Aprendizagem Motora: uma proposta de contextualização baseada no paradigma ecológico humano de Bronfenbrenner, fundamentada na psicologia histórico-cultural de
Vygotsky. Tese de Doutorado. CEFD, UFSM, 1999.

STEFANELLO, J. M. F. A participação da criança no desporto competitivo: uma tentativa de operacionalização e verificação empírica da proposta teórica de Urie Bronfenbrenner. Tese de Doutorado. Universidade de Coimbra, 1999.

VYGOTSKY, L. S. A formação social da mente. São Paulo: Martins Fontes, 1989.

TRIVIÑOS, A. N. S. Introdução à Pesquisa em Ciências Sociais: A pesquisa qualitativa em educação. São Paulo: Atlas, 1987.

Endereço:

Silvia Teixeira de Pinho

Av. Nações Unidas, 500 - Nossa Sra das Graças Porto Velho RO Brasil

78915-040

e-mail: silvia_esef@yahoo.com.br

Recebido em: 4 de agosto de 2009

Aceito em: 13 de abril de 2010.

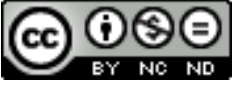

Motriz. Revista de Educação Física. UNESP, Rio Claro, SP, Brasil - elSSN: 1980-6574 - está licenciada sob Licenca Creative Commons 